\title{
Comparing the Patient's Satisfaction With Educational Performance of the Physicians and the Nurses
}

\author{
Fatemeh Heshmati Nabavi, ${ }^{1}$ Mohammad Rajabpoor, Javad Mahmoodi, ${ }^{3}$ ZohrePouresmail, ${ }^{2, *}$ \\ and Taktam Mikaniki ${ }^{4}$ \\ ${ }_{1}^{1}$ Assistant Professor, Nursing Management Department, Nursing and Midwifery School, Mashhad University of Medical Sciences, Mashhad, IR Iran \\ ${ }^{2}$ Medical Surgical Nursing Department, Mashhad University of Medical Sciences, Mashhad, IR Iran \\ ${ }^{3}$ BSN, Open Heart Surgery Department, Imam Reza Hospital, Mashhad University of Medical Sciences, Mashhad, IR Iran \\ ${ }^{4}$ BSN, Nursing Management Department, Treatment Affairs, Mashhad University of Medical Sciences, Mashhad, IR Iran \\ *Corresponding author: Zohre Pouresmail, MSc Student, Nursing and Midwifery School, Mashhad University of Medical Sciences, Ebn-e Sina St., Doktora Crossing, Mashhad, IR Iran. \\ Tel:+985118591511-3, Fax:+985118597313, E-mail: pouresmailz921@mums.ac.ir
}

Received 2015 June 25; Revised 2015 September 15; Accepted 2015 November 1.

\begin{abstract}
Background: Patient education is one of the most basic patient rights. It has multiple benefits including decreased patient anxiety, increased patient adherence to treatment programs, and ultimately improvement of healthcare service quality. Patients, especially those with chronic conditions, make daily decisions about illness self-management. Given the nature of their professions, physicians and nurses have more responsibility regarding patient education.

Objectives:This study compared patient's satisfaction with educational performance of physicians to that of nurses at Mashhad University of Medical Sciences.

Patients and Methods: This descriptive cross-sectional study was performed in 2013 with 231 patients hospitalized in Mashhad-based hospitals affiliated with Mashhad University of Medical Sciences. Sampling was performed nonrandomly using quota sampling. Data collection tools were a demographic information questionnaire and separate questionnaires for satisfaction with educational performance of physicians and nurses. Data were analyzed in SPSS (11.5) using t-and Wilcoxon's tests.

Results: There were 231 participants (men: 55.3\%). Of them, 58.9\% of the patients were satisfied with educational performance of nurses and 50.6\% were satisfied with that of physicians. To compare satisfaction with physicians' $(66.2 \pm 23.4)$ and nurses' (74.1 \pm 24.1$)$ educational performances, mean total satisfaction points out of 100 were obtained. Independent $t$-test showed a significant difference in this regard $(\mathrm{P}=0.02)$.

Conclusions: Nurses and physicians' educational roles should be examined in the authors' healthcare system. Further surveys are needed to find and assess individual and organizational approaches to improve physicians' and nurses' educational performances.
\end{abstract}

Keywords: Physicians, Nurses, Patient Satisfaction, Education, Patients

\section{Background}

Education is a fundamental patient right. Such education informs patients regarding their medical condition (1), medical intervention, and choices regarding treatment type (2). Such education can be helpful for improving health services quality (1), patient satisfaction (3), medical program adherence, patient independence (4), decreased anxiety and mortality (5), decreased side effects of diseases and treatment, and increased positive results (6). Patient education can be defined as a set of formal and informal activities completed by health staff to achieve health improvement by providing information and required knowledge of the skills needed for health and disease management (7). Such education includes different and integrated stages completed in an orderly and sequential manner (2). Therefore, the importance of educational programs that teach patients about self-managing their disease has been emphasized as an important function for reducing disease burden and improving patients' quality of life. Patients with chronic conditions make daily decisions about illness self-management (8). They require education consonant with disease stage.

The world health organization approaches health education as a team and interdisciplinary activity and recommends health staff consider patient education a medical measure to improve efficiency of health activities (9). To improve efficiency of patient education, they must be provided with health education at two levels: first healthcare and hospital (10). In this regard, physicians and nurses are key medical team members to provide such education to patients.

Patients' satisfaction with health education provided

Copyright (C) 2016, Ahvaz Jundishapur University of Medical Sciences. This is an open-access article distributed under the terms of the Creative Commons Attribution-NonCommercial 4.0 International License (http://creativecommons.org/licenses/by-nc/4.0/) which permits copy and redistribute the material just in noncommercial usages, provided the original work is properly cited. 
by health staff is a key index of quality and effectiveness of health service $(9,11)$. Dissatisfaction and negligence of the patients' viewpoints threatens realization of preferred results by the health system (12). As far as patients are concerned, they have conveyed their dissatisfaction toward their healthcare systems and requested more information and participation in their health decisions (informed consent), thus showing a greater sense of responsibility for their own health (13).

Taking into account the viewpoints of the service users provides the infrastructure of service organizations; it also is a way of increasing public participation. When it comes to health service organizations, taking into account patients' viewpoints and winning their satisfaction is a measure of service quality; by doing this, innovation and improvement of service quality are realized (6).

In light of this, patient's satisfaction became a key index of health services quality and measuring nurses' performance in health service centers in the 1990s in the USA (12). In Iran, the Ministry of Health and Medical Education ordered all hospitals in 2011 to measure patients' satisfaction periodically and take required measures to improve patient satisfaction (14).

In a study at Kano University, USA, regarding patient's satisfaction with physicians and nurses' performances, the majority of the patients (95.5\% and $96.1 \%$, respectively) expressed satisfaction (15). Studies in Iran indicated that minimum satisfaction with physicians and nurses was with education services. This highlights the necessity for more accurate surveys and timely programming (14). Peyrovi et al. (2009) showed that the highest and lowest levels of patient satisfaction were with "technical and professional" healthcare services in intensive care wards and "patient educations services" in surgery wards provided by nurses (6). Kohan et al. (1996) also showed that patients' highest and lowest satisfaction levels were with the nurses' services regarding "healthcare behavior" and "educating necessary points at discharge," respectively. They also indicated that patient satisfaction regarding provision of healthcare services by the physicians was higher than the services by the nurses (16).

Several studies have been conducted concerning patient satisfaction from different approaches such as hospital facilities and the way services are provided. However, few studies have been done on patient education services.

\section{Objectives}

Taking into account that proper education helps increase patients' satisfaction with the services, the importance of patient education and lack of attention to it by Iranian nurses and doctors, and since epidemiological studies provide the basis for health policy makers' decision-making, the present study is an attempt to survey and compare patient's satisfaction with educational performances of physicians and nurses.

\section{Patients and Methods}

The study was completed as a descriptive cross-sectional study in Mashhad-based hospitals affiliated with University of Medical Sciences (2013). Study population was comprised of all patients hospitalized in hospital general wards. Overall, 231 patients expressed their willingness to participate in the study and the surveys were completed with these patients.

Among the main inclusion criteria were at least three days hospitalization on the ward, consciousness, and literacy (patient or family members). Unconscious patients were removed from the study. To set the minimum sample groups, the mean attribute estimate formula was used. To estimate accuracy, maximum acceptable error, and p-value, a pilot study was completed with 30 patients. Level of confidence was set at 95\% ( $\alpha=$ 0.05). As the estimates recommended, 231 participants were selected. At first, six educational hospitals affiliated with Mashhad Medical Science University were selected from 12 hospitals. The selection was based on hospital features such as their field of expertise, number of patients, and city districts. The authors attempted to ensure that the selection was a representative set of hospitals of all city districts and also all special medical services. Sampling was completed through nonrandom quota sampling. Based on the rate of hospitalized patients in general wards of Imam Reza hospital (one of the two specialized leading educational and medical hospitals); Hashemi Nejad hospital (specialized hospital in an underdeveloped district); Dr. Sheikh Hospital (pediatric hospital); Omid hospital (cancer hospital); Taleghani, Shariati, and Ibn Sina Hospitals (psychology centers); and Montaserieh Hospital (implantation hospital) to the total capacity of these hospitals, sample rates of each center to the total study population were obtained. The participants were selected using convenience sampling after securing permission from the hospitals' authorities. To this end, the researchers visited the wards during three work shifts (morning, afternoon, night) to select the participants. After determining the potential participants, the authors outside of the treatment team briefed the patients or their family members and provided them with the questionnaires. The authors were ready to answer any question regarding the questionnaires; finally, the completed questionnaires were collected. This process was repeated until the number of participants in each hospital met the quota. The participants expressed their desire to participate in the study before being asked to complete the questionnaires.

Data gathering tools were a demographical information questionnaire (age, gender, marital status, name, surgery record, hospitalization record, and term of hospitalization), nurses' educational performance questionnaire, and physicians' educational performance questionnaire. The physicians' educational performance 
questionnaire was designed based on the nurses' educational performance questionnaire from another study with some modifications and after ascertaining content validity through experts' comments (17). Reliability of the questionnaire was ensured through internal homogeneity and Cronbach's alpha ( $\alpha=0.89$ ).

The patient satisfaction with nurses and physician's educational performances comprised 12 close-ended statements ( satisfied $=2$, relatively satisfied $=1$, and not satisfied $=0$ ). Maximum and minimum points of the questionnaires were 24 and 0 respectively. For improved interpretation, the points were scaled up to 100 points.

The collected data were analyzed in SPSS (11.5) using descriptive and analytical statistics. Independent t-test was used to compare mean satisfaction with the physicians and nurses' educational performances. Pearson correlation coefficient was used to survey the relationship between age and satisfaction with the physician's educational performance; Spearman correlation coefficient was used to survey relationships between surgery record of the patients and their satisfaction with the nurse's educational performance $(\mathrm{P}=0.05)$.

\subsection{Ethical Considerations}

This study was conducted after obtaining the confirmation of the Mashhad Ethics Committee and the informed consent from all participants in the study (ruling number: 940048).

The participants were informed that their information was preserved as private and the information would be used for analysis.

\section{Results}

Out of 350 distributed questionnaires, 231 were returned. Female and male participants constituted $44.7 \%$ (102) and 55.3\% (126) of the sample group respectively. Average and standard deviation of hospitalization course was $8.21 \pm 6.75$ days. In addition, average age of the participants was $40.91 \pm 18.03$ years. The rest of demographical information is listed in Table 1.

As listed in Table 2, maximum satisfaction level with the nurses' educational performance was $59.3 \%$ in the field of medicine precautions and minimum level of satisfaction was $15.5 \%$ in the field of re-starting daily activities. Furthermore, maximum satisfaction level with the physician's educational performance was $72.2 \%$ in the field of treating the patients respectfully and minimum level of satisfaction was $24.2 \%$ in the field of re-starting daily activities.

Comparing satisfaction scores of the nurses and the physicians, the results of Wilcoxon's test showed that satisfaction with the nurse's educational performance was significantly higher than that of physicians in the fields of medicine precautions, diet, permitted activities, and re-starting daily activities. Regarding other fields such as explaining the patient's condition regarding their disease $(P=0.21)$, understandability of the education $(P=0.62)$, and giving satisfactory answers to the patient's questions ( $\mathrm{P}=0.31)$, no significant differences were observed between the nurses and physicians' educational performances. Comparing the total satisfaction points with the physicians' educational performances $(66.2 \pm 23.4)$ to that of nurses $(74.1 \pm 24.1)$ by independent t-test showed significant differences $(\mathrm{P}=0.02)$. In short, $58.9 \%$ and $50.6 \%$ of the patients were satisfied with educational performance of the nurses and physicians, respectively.

The Pearson correlation coefficient showed a significant relationship between the patient's age and satisfaction with the physician's performance $(\mathrm{p}=0.001, \mathrm{r}=0.21$ ).

\begin{tabular}{|c|c|}
\hline Index & Values \\
\hline \multicolumn{2}{|l|}{ Surgery record } \\
\hline Yes & $117(50.7)$ \\
\hline No & $114(49.3)$ \\
\hline Total & $231(100)$ \\
\hline \multicolumn{2}{|l|}{ Education } \\
\hline Elementary & $89(47.8)$ \\
\hline High school & $72(38.7)$ \\
\hline Higher education & $25(13.4)$ \\
\hline Total & $231(100)$ \\
\hline \multicolumn{2}{|l|}{ Occupation } \\
\hline While collar & $25(13.4)$ \\
\hline Blue collar & $37(19.8)$ \\
\hline Farmer & $10(5.3)$ \\
\hline Housewife & $73(39.0)$ \\
\hline Others & $42(22.5)$ \\
\hline Total & $231(100)$ \\
\hline \multicolumn{2}{|l|}{ Ward } \\
\hline Surgical & $52(22.5)$ \\
\hline Medical & $109(47.2)$ \\
\hline Emergency & $36(15.6)$ \\
\hline $\mathrm{CCU}$ & $4(1.7)$ \\
\hline Gynecology & $19(8.2)$ \\
\hline Psychology & $11(4.8)$ \\
\hline Total & $231(100)$ \\
\hline
\end{tabular}

${ }^{\mathrm{a}}$ Data are presented as No. (\%). 
Heshmati Nabavi F et al.

\begin{tabular}{|c|c|c|c|c|c|c|c|}
\hline \multirow[t]{2}{*}{ Statement } & \multicolumn{3}{|c|}{$\begin{array}{c}\text { Satisfaction With Nurses' } \\
\text { Performance }\end{array}$} & \multicolumn{3}{|c|}{$\begin{array}{c}\text { Satisfaction With Physicians' } \\
\text { Performance }\end{array}$} & \multirow[t]{2}{*}{ PValue } \\
\hline & Satisfied & $\begin{array}{c}\text { Relatively } \\
\text { Satisfied }\end{array}$ & Not Satisfied & Satisfied & $\begin{array}{l}\text { Relatively } \\
\text { Satisfied }\end{array}$ & Not Satisfied & \\
\hline $\begin{array}{l}\text { The nurses/physicians spent time explain- } \\
\text { ing my diseases }\end{array}$ & $137(59.3)$ & $78(33.8)$ & $16(6.9)$ & $126(54.5)$ & $85(36.8)$ & $20(8.6)$ & $0.21(-1.25)$ \\
\hline $\begin{array}{l}\text { The nurses/physicians spent time explain- } \\
\text { ing medications and how to take them }\end{array}$ & $135(58.4)$ & $75(32.5)$ & $21(9.1)$ & $127(55)$ & $80(34.6)$ & $24(10.4)$ & $0.41(-0.81)$ \\
\hline $\begin{array}{l}\text { The nurses/physicians spent time explain- } \\
\text { ing precautions about the medications }\end{array}$ & $132(57.1)$ & $71(30.7)$ & $28(12.1)$ & $120(51.9)$ & $69(29.4)$ & $43(18.6)$ & $0.04(-2.05)$ \\
\hline $\begin{array}{l}\text { The nurses/physicians spent time explain- } \\
\text { ing what I should eat }\end{array}$ & $134(58)$ & $64(27.7)$ & $33(14.3)$ & $106(45.9)$ & $78(33.8)$ & $47(20.3)$ & $\begin{array}{l}0.002 \\
(-3.05)\end{array}$ \\
\hline $\begin{array}{l}\text { The nurses/physicians spent time explain- } \\
\text { ing what activity I'm allowed to do }\end{array}$ & $120(51.9)$ & $78(33.8)$ & $33(14.3)$ & $96(41.6)$ & $89(38.5)$ & $46(19.9)$ & $\begin{array}{l}0.006 \\
(-2.73)\end{array}$ \\
\hline $\begin{array}{l}\text { The nurses/physicians spent time explain- } \\
\text { ing how I should restart daily activities }\end{array}$ & $113(48.9)$ & $83(35.9)$ & $35(15.2)$ & $85(36.8)$ & $90(39)$ & $56(24.2)$ & $0.00(-3.58)$ \\
\hline $\begin{array}{l}\text { The nurses/physicians spent time explain- } \\
\text { ing when rechecking was required and } \\
\text { follow up plans }\end{array}$ & $122(52.8)$ & $80(34.6)$ & $29(12.6)$ & $114(49.4)$ & $76(32.9)$ & $41(17.7)$ & $0.11(-1.57)$ \\
\hline $\begin{array}{l}\text { The nurses/physicians' education was } \\
\text { understandable }\end{array}$ & $133(57.6)$ & $85(36.8)$ & $13(5.6)$ & $136(58.9)$ & $74(32)$ & $21(9.1)$ & $0.62(-0.49)$ \\
\hline $\begin{array}{l}\text { The nurses/physicians' behavior was with } \\
\text { respect. }\end{array}$ & $153(66.2)$ & $58(25.1)$ & $20(8.7)$ & $168(72.7)$ & $51(22.1)$ & $12(5.2)$ & $0.028(-2.19)$ \\
\hline $\begin{array}{l}\text { The nurses/physicians' answers were } \\
\text { satisfactory }\end{array}$ & $128(55.4)$ & $82(35.5)$ & $21(9.1)$ & $122(52.8)$ & $83(35.9)$ & $26(11.3)$ & $0.31(-.99)$ \\
\hline $\begin{array}{l}\text { The nurses/physicians saw/called my fam- } \\
\text { ily and answered their questions }\end{array}$ & $128(52.4)$ & $78(33.8)$ & $32(13.9)$ & $107(46.3)$ & $83(35.9)$ & $41(17.7)$ & $0.07(-1.81)$ \\
\hline $\begin{array}{l}\text { The nurses/physicians' educations were } \\
\text { generally satisfactory }\end{array}$ & $136(58.9)$ & $74(32)$ & $21(9.1)$ & $117(50.6)$ & $86(37.2)$ & $28(12.1)$ & $0.02(-2.27)$ \\
\hline
\end{tabular}

${ }^{\mathrm{a}}$ Data are presented as No. (\%).

\section{Discussion}

Patient satisfaction with educational performances of physicians and nurses was compared. In general, the patients were more satisfied with the nurses' educational performance than that of the physicians. Educational performance of the nurses was better than that of the physicians in education fields of how to use medicine and medicine precautions. In addition, there was no difference between the physicians and nurses regarding understandability of explanations. Minimum satisfaction level with the nurses and the physicians was observed regarding diet and restarting daily activities.

Different studies have shown that the society, patients, nurses, and medicine students do not have similar attitudes regarding nurses' roles. Some authors have reported that the public does not have correct viewpoints regarding nurses' roles and their role regarding patients' education is mostly neglected. Moreover, one study showed significant differences between perception of the nurses' role among medicine and nursing students so that the latter group, despite the former, believed that ed- ucating patients was not part of their tasks (18). The point is, however, that patient education has become part of the physician's role since 1986. Studies in Iran have dealt with practical obstacles to patient education. Dehghani et al. (2014) maintained that the nurses believed that lack of enough time, understaffing, and no recognition of the nurses' effort to train the patients were the main obstacles to patient education in hospitals (19). These issues, of course, are within the scope of management's tasks.

However, such problems should not prevent the nurses from doing their tasks as the patients tend to consider a nurse passionate and skillful when they show professional capability in doing their role. On the other hand, when the nurses successfully develop their skills, they will enjoy wider options to take on new roles and responsibilities. Studies have shown that failure to fulfill or finish professional tasks by the nurses leads to poor and problematic nursing services. Thus, by developing and improving their professional capabilities and taking on a variety of roles as health service providers, the nurses can 
take a great step toward development of the nursing profession and improvement of its standing in the society.

Karimi et al. (2006) showed that the majority of people adopted positive attitudes toward the roles and values of nurses. Currently, the society is ready to develop better perception of the roles and position of the nurse; along with development of medical-health system, better nursing services must be provided (20). There is a general perception that the nurse is a knowledgeable person regarding health issues and many respect the nurses' professional comments regarding health-related matters. As a mentor, the nurse can explain and promote healthy habits and beliefs. Therefore, given the important role of nurses and the priority of prevention over treatment, the nurse must be more active in public education field (18). This is proven by high patient satisfaction rates with educational performance of the nurses especially regarding medicine precautions and side effects.

To explain the reasons for different viewpoints, one may point out improvement of the general condition of the nursing profession. Large numbers of studies completed on different aspects of patient education have been used to improve clinical and education conditions. In addition, different studies have reported higher satisfaction with the nurses' educational performance among patients compared with that of the physicians. Sandhu consistently reported, for instance, that the patients were generally more satisfied with the education services by the nurses compared to the physicians (21). Probably one explanation for this is that the nurses spend more time with the patients.

Concerning satisfaction with educational performance of the physicians, the results showed satisfaction level higher than the mean (66 - 100). However, literature review on studies in Iran did not show the obstacles to education services by the physicians. Still, the findings can be interpreted by surveying similar studies. One of the aspects of patient education is the terms of interaction between the trainer and trainee. That is, to gain the maximum result and perception out of the education, the course must be long enough. Studies have shown that the patient has specific concerns and needs more attention from the physician (22). Such concerns include the specific problem the patient has at the moment, the cause of disease, severity, prevention, required measures for treatment such as medical tests, prescribed medicine, referral to specialist practitioner, or securing documents to explain their absence from work. What is important for the patients is different from what is in the mind of the physician; thus, the patient's concerns are neglected and in some cases leads to dissatisfaction (23). On the other hand, Makarem et al. reported that physician members of the faculty of Mashhad Medical University barely showed active listening expressions when they were examining the patients (24).

Another aspect of education is active listening. Olson defined active listening as "to understand what the speaker is saying, how they feel and then retransferring the perceived message to the speaker." Again, Makarem et al. (2012) showed that active listening behavior is barely seen by the physician faculty of Mashhad Medical Science University. The patients barely find the chance to express their problem, which is probably due to the large number of patients that a physician has to attend to (24).

It is notable that another aspect of education is the trainer's satisfaction with their job and Sandhu reported that nurses are more satisfied with their educational performance comparing with the physicians (21).

The fact that the principles of patient education are covered in the B.A. nursing curriculum as a one-credit course explains partially why nurses perform better than physicians in this regard. Given that interpersonal communication techniques are taught to the nursing and medicine students in medical environments and they tend to copy their professors and clinical personnel, it is possible to design frameworks to emphasize such skills.

One of the key measures of healthcare services quality is the patient's satisfaction with healthcare services (10, 25). In fact, surveys of patients' satisfaction are a managerial tool that highlights executive shortcomings at large scale (9). Despite the popularity of the idea of surveying the patient's satisfaction as a measure of healthcare quality, some experts believe that the patients are not reliable sources of information regarding quality of the services as they possess subjective attitudes regarding quality of the services (4). In fact, the patient's satisfaction is an emotional reaction, through which they express positive or negative emotions regarding the nursing services (1).

Studies in developing countries on perception of the patients regarding quality of services and their satisfaction with the services have shown significant relationships between communication between the health services providers and patients and patient satisfaction with the health services $(P=0.01)(23)$. On other hand, the patient's satisfaction with the quality of the health services is influenced by their expectations (26). Given this, precautions must be taken in interpretation of the findings. Satisfaction of half of the participants with the services cannot be interpreted as good quality of the health services in the hospitals under study. Further studies are required to measure satisfaction based on other measures of quality.

The findings showed that the patients are generally more satisfied with educational performance of the nurses compared to that of the physicians. To increase the patient satisfaction, medicine students' communication skills can be improved by devising a one-credit course in the curriculum. In addition, considering the current obstacles in the nurses and the physicians' way of performing their education role, managerial intervention to remove the obstacles and improve educational performance is recommended.

Limitations of this study included lack of random sampling and general assessment of patient in all hospital departments. However, comparing the educational per- 
formance of doctors and nurses was conducted for the first time in Iran; there is a need for more studies to compare satisfaction with educational performance of the nurses and physicians based on more indices of quality. Results of these studies can be used to improve quality of education services by the nurses and the physicians.

\section{Acknowledgments}

The present paper is part of research plan No. 940048 approved by the research department of Mashhad University of Medical Sciences. Researchers thank and appreciate Vice Chancellor of research because of its financial support and also all the patients participated in this study.

\section{Footnotes}

Authors' Contribution:Study concept and design: Fatemeh Heshmati Nabavi, Javad Mahmoodi, Taktam Mikaniki and Mohammad Rajabpoor; analysis and interpretation of data: Mohammad Rajabpoor and Fatemeh Heshmati Nabavi; drafting of the manuscript: Mohammad Rajabpoor, Fatemeh Heshmati Nabavi and Zohre Pouresmail; critical revision of the manuscript for important intellectual content: Fatemeh Heshmati Nabavi, Zohre Pouresmail and Javad Mahmoodi; statistical analysis: Mohammad Rajabpoor and Fatemeh Heshmati Nabavi.

Funding/Support:The author(s) disclosed receipt of the following financial support for the research and/or authorship of this article: This project was supported by funding from Mashhad University of Medical Sciences.

\section{References}

1. Ortiz J, Wang S, Elayda MA, Tolpin DA. [Preoperative patient education: can we improve satisfaction and reduce anxiety?]. Rev Bras Anestesiol. 2015;65(1):7-13. doi: 10.1016/j.bjan.2013.07.009. [PubMed: 25497743]

2. Kalantari S, Najafi K, Abbaszadeh A, Sanagoo A, Borhani F. Nurses' Perception of Performance of Patient Education. Jentashapir J Health Res. 2012;2(4):167-74.

3. Noorossana R, Rezaeian S, Moradi S, Rezaeian Z. Patient satisfaction of general practitioners: A cross-sectional study.J Med Ethics. 2012;22(6):161-84.

4. Oliveira VC, Refshauge KM, Ferreira ML, Pinto RZ, Beckenkamp PR, Negrao Filho RF, et al. Communication that values patient autonomy is associated with satisfaction with care: a systematic review. J Physiother. 2012;58(4):215-29. doi: 10.1016/S18369553(12)70123-6. [PubMed: 23177224]

5. Banki F, Ochoa K, Carrillo ME, Leake SS, Estrera AL, Khalil K, et al. A surgical team with focus on staff education in a community hospital improves outcomes, costs and patient satisfaction. Am J Surg. 2013;206(6):1007-14. doi: 10.1016/j.amjsurg.2013.08.015. [PubMed: 24139667]

6. Peyrovi H, Bahadori A, Ashghali-Farahani M, Haghani H. Comparison of in-patients' satisfaction with different domains of nursing care. QJ Nurs Manag. 2013;2(1):59-66.

7. Langen I, Myhren H, Ekeberg O, Stokland O. Patient's satisfac- tion and distress compared with expectations of the medical staff. Patient Educ Couns. 2006;63(1-2):118-25. doi: 10.1016/j. pec.2005.09.008. [PubMed:16242897]

8. Bodenheimer T, Lorig K, Holman H, Grumbach K. Patient self-management of chronic disease in primary care. JAMA. 2002;288(19):2469-75. [PubMed:12435261]

9. Drennan J, Naughton C, Allen D, Hyde A, O'Boyle K, Felle P, et al. Patients' level of satisfaction and self-reports of intention to comply following consultation with nurses and midwives with prescriptive authority: a cross-sectional survey. Int J Nurs Stud. 2011;48(7):808-17. doi: 10.1016/j.ijnurstu.2011.01.001. [PubMed: 21257171]

10. Rosenqvist U. Patient education-new trends in Sweden. Patient Educ Counsel. 2001;44(1):55-8.

11. Alturki M, Khan TM. A study investigating the level of satisfaction with the health services provided by the Pharmacist at ENT hospital, Eastern Region Alahsah, Kingdom of Saudi Arabia. Saudi Pharm J. 2013;21(3):255-60. doi: 10.1016/j.jsps.2012.09.001. [PubMed: 23960841]

12. Billmann F, Bokor-Billmann T, Voigt J, Kiffner E. Effects of a cost-effective surgical workflow on cosmesis and patient's satisfaction in open thyroid surgery. Int J Surg. 2013;11(1):31-6. doi: 10.1016/j. ijsu.2012.11.004. [PubMed: 23164990]

13. Deccache A, Aujoulat I. A European perspective: common developments, differences and challenges in patient education. Patient Educ Counsel. 2001;44(1):7-14. doi: 10.1016/s07383991(01)00096-9.

14. Seyfe Rabiee M, Shahidzade M. Satisfaction of patients hospitalized in private hospitals covered Hamadan and its influencing factors. Pyesh. 2006;5(4):271-9.

15. Miseviciene I, Milasauskiene Z. [Patient satisfaction with the work of the hospital medical personnel]. Medicina. 2001;38(5):559-65. [PubMed:12474691]

16. Kohan S, Ferayduni ZH, Alizade S, Bahrampour A. Comparison of patient satisfaction and the delivery of nursing and medical care. J Razi Nurs Midwifery School. 2003;1(3):44-50.

17. Memarian R, Vanaki Z. The Effect of Implementing Clinical Supervision Model on the Patient Education Outcomes. $J$ Health Promot Manag. 2012;1(3):28-36.

18. Aliakbari F, Aslani Y. Comparison between the attitude of nurses, nursing students and patients about nurses, roles in educational hospitals of Shahrekord. JClin Nurs Midwifery. 2013;2(2):10-7.

19. Dehghani A, Orang M, Abdollahi FS, Parvianian NA, Vejdani M. Barriers to patient education in clinical care; viewpoints of nurses. Iran J Med Educ. 2014;14(4):332-41.

20. Karimi Z. The nurse role and value from yasouj people view point. Dena. 2005;1(3):43-51.

21. Sandhu H, Dale J, Stallard N, Crouch R, Glucksman E. Emergency nurse practitioners and doctors consulting with patients in an emergency department: a comparison of communication skills and satisfaction. Emerg Med J. 2009;26(6):400-4. doi: 10.1136/ emj.2008.058917. [PubMed:19465607]

22. Lewin B. Patient satisfaction with physician responses during interactions prompted by pharmaceutical advertisements. Soc Sci J. 2013;50(4):491-500. doi:10.1016/j.soscij.2013.03.002.

23. Afkham Ebrahimi A, Nasr Esfahani M, Saghafi N. Patients' expectations and satisfaction with their treating physician. Razi J Med Sci. 2004;11(41):367-75.

24. Makarem A, Movaffaghi Z, Hosseini FS, Beiraghi N, Heshmati Nabavi F, Khaje Daluee M. Clinical Medical Teachers' Competency of Active Listening in Mashhad University of Medical Sciences. Iran J Med Educ. 2013;12(12):935-46.

25. Harkin Kirwan P. Unravelling the confusion of clinical supervision. Nurs Midwifery Educ Train. 2000;12(2):40-5.

26. Karami Kabir N, Lotfi M. The Effective Factors on Satisfaction from the View Point of Patients at the Emergencywards in Tabriz emam and Sina Hospitals,(2010). Proc Soc Behav Sci. 2012;31:750-5. 